\title{
TEATRO DO OPRIMIDO E PROMOÇÃO DA SAÚDE: TECENDO DIÁLOGOS
}

\author{
TEATRO DEL OPRIMIDO Y PROMOCIÓN DE LA SALUD: \\ TEJIENDO DIÁLOGOS
}

\author{
THEATRE OF THE OPPRESSED AND HEALTH PROMOTION: \\ BUILDING DIALOGUES
}

\author{
César Augusto Paro ${ }^{1}$ \\ Neide Emy Kurokawa e Silva²
}

Resumo O estudo aqui apresentado buscou discutir as contribuições do teatro do oprimido na promoção da saúde, visando a colaborar para a consolidação desse diálogo de maneira que as repercussões no desenvolvimento das experiências práticas sejam potencializadas. Dentre as duas principais vertentes da promoção da saúde, registra-se a incompatibilidade entre os alicerces éticos, estéticos e políticos que fundamentam o teatro do oprimido e os pressupostos teóricos da corrente behaviorista, uma vez que esse teatro se afasta de qualquer tentativa de domesticação dos corpos e de normatização de comportamentos, hábitos e estilos para que sejam atingidos padrões (classificados por alguns como) saudáveis. Já com relação à perspectiva da nova promoção da saúde, de politização e busca de aproximação entre saberes científicos e técnicos com os saberes populares, observaram-se maiores consonâncias entre ela e o teatro do oprimido, a partir do momento em que ambos logram o fortalecimento de práticas cidadãs questionadoras do status quo e de mudanças sociais em prol de uma transformação libertária e crítica.

Palavras-chave teatro do oprimido; empoderamento; promoção da saúde; cidadania; participação popular.
Abstract The aim of this study is to discuss the contributions of the theatre of the oppressed in health promotion and to collaborate with the improvement of the consolidation of this dialogue in practice experiences. Comparing the main perspectives of health promotion, there is a mismatch between the ethical, aesthetic and political foundations of the theatre of the oppressed and the theoretical assumptions of the behaviorist health promotion, because this kind of theatre pulls away from any attempt at domestication of bodies and norms of behavior, habits and lifestyles to reach healthy standards. There are greater consonance between the theatre of the oppressed and the new health promotion, its politicization and its searches to approach scientific and technical knowledge with popular knowledge, since both seek the fortification of humane practice that put in question the status quo and the social change towards a libertarian and critical transformation.

Keywords theatre of the oppressed; empowerment; health promotion; citizenship; popular participation. 


\section{Introdução}

Na área da saúde, principalmente a promoção da saúde, tem se observado um movimento de aproximação cada vez maior com as linguagens artísticas no seu cotidiano de trabalho. Esse cruzamento vem ocorrendo de diversas formas e envolve uma pluralidade de saberes e práticas.

Dentre as linguagens artísticas, o teatro do oprimido parece surgir como uma opção oportuna para as ações de promoção da saúde, sobretudo diante das aspirações democráticas e participativas do Sistema Único de Saúde (SUS). O estudo que deu origem a este artigo ${ }^{3}$ buscou trazer a discussão sobre essa possibilidade de articulação entre teatro do oprimido e promoção da saúde. Para tanto, realizou-se, inicialmente, uma retomada histórica do teatro do oprimido, com ênfase no contexto histórico em que surgiu, seus pressupostos conceituais, objetivos e modo de funcionamento, seguida de contextualização sobre a promoção da saúde, pontuando a pluralidade de conceitos e práticas que emergem desse constructo - o que repercute, consequentemente, em ações heterogêneas nesse campo. A partir da constituição desses cenários, discutiu-se a relação entre teatro do oprimido e promoção da saúde, visando à consolidação desse diálogo de maneira que as repercussões no desenvolvimento das experiências práticas sejam potencializadas.

\section{Teatro do oprimido: histórico, características e caminhos possíveis}

O teatro do oprimido é um método pedagógico, social, cultural, político e terapêutico criado por Augusto Boal (1931-2009), importante teatrólogo, diretor, dramaturgo e ensaísta carioca. Ele é definido pelo seu criador como

(...) um sistema de exercícios físicos, jogos estéticos, técnicas de imagem e improvisações especiais, que tem por objetivo resgatar, desenvolver e redimensionar essa vocação humana, tornando a atividade teatral um instrumento eficaz na compreensão e na busca de soluções para problemas sociais e interpessoais (Boal, 2002, p. 28-29).

O método do teatro do oprimido ancora-se em dois princípios fundamentais: a transformação do espectador, ser passivo, recipiente, depositário, em 'espect-ator', ou seja, protagonista da ação dramática, sujeito, criador, transformador; e não trata apenas de refletir sobre o passado, mas também de preparar o futuro, isto é, deve-se transformar todas as situações vividas no espaço cênico em um ensaio para a transformação da realidade. Nesse sentido, Boal (1979, p. 18) criticava: “basta de um teatro que apenas interprete a realidade: é necessário transformá-la!". 
No âmbito da história do teatro brasileiro, o teatro do oprimido é identificado como um dos representantes do teatro-político, dada sua inserção no debate sobre a realidade social mediante um aparato político-estético ancorado na criação dinâmica de peças teatrais. O contexto político-social do momento de sua criação era o da ditadura militar, que havia se instaurado a partir de 1964. Esse período foi caracterizado por instrumentos de coerção à liberdade de expressão com a perseguição de artistas que tinham preocupações sociais e políticas. Em resposta a esse movimento, o teatro do oprimido surgiu para refutar a ideia da arte isolada da vida e se desdobrou da gestão de práticas de resistência democrática que compunham o cenário das lutas sociais do país no período da repressão política (Teixeira, 2007).

Em 1970, Boal regressou ao Brasil após excursões com o Teatro de Arena em alguns países americanos e desenvolveu as primeiras experiências com o teatro-jornal, técnica que, juntamente com o público, desconstrói notícias de jornais diários, teatralizando-as. Essa experiência, considerada semente do teatro do oprimido, durou pouco tempo, porque Boal foi preso, torturado e exilado no ano seguinte. Durante os 13 anos de exílio, ele desenvolveu outras técnicas e exercícios em todos os países que foi percorrendo (Barbosa, 2011). Em 1973, publicou a obra Teatro do oprimido e outras poéticas politicas, que congrega e sistematiza essas experiências, considerado um marco da criação do teatro do oprimido (Boal, 2013). Esse método ganhou projeção internacional, contemplando iniciativas nos cinco continentes (International Theatre of the Oppressed Organization, 2015).

Boal (2013) defendia a ideia de que todo teatro é político, uma vez que todas as atividades humanas são políticas. Segundo o autor, pelo fato de o teatro ser uma arma eficiente para se fazer/falar de política, as classes que se encontram no poder se apropriam permanentemente dele e o usam como instrumento de dominação. Ao buscar expor como esse processo ocorreu ao longo da história, Boal se remetia à Grécia antiga, quando a aristocracia retirava a livre participação do povo da esfera do teatro: promovia-se uma divisão entre aqueles que representavam e aqueles que assistiam, sendo que este último papel cabia ao povo, que deveria ficar sentado, passivo e receptivo. Os protagonistas, por sua vez, eram sempre os aristocratas, e a representação fazia alusão a uma ideologia dominante e, por conseguinte, opressora. O denominado sistema trágico coercitivo de Aristóteles constituiu o primeiro sistema poético-político de intimidação do espectador, funcionando para diminuir, aplacar, satisfazer e eliminar tudo o que pudesse romper o equilíbrio social, como os impulsos revolucionários/transformadores.

Ao se opor a essa proposta do teatro como purgação dos elementos definidos como antissociais por alguns poucos, o teatro do oprimido propõe recolocar o povo em seu lugar de origem por meio da construção e trabalho 
de temas populares com a participação ativa dos 'espect-atores' na prática teatral. Para tanto, assume-se o pressuposto de que o ser humano é naturalmente teatral, dado que ele se vale o tempo inteiro de representações corporais nas relações (como o tom de voz, a expressão facial e a postura corporal), assim como da intepretação desses signos nas outras pessoas (Boal, 1979). Com esse dispositivo, almeja-se a transformação dos oprimidos em seres livres, que têm como condição fundamental a conquista dos meios de produção teatral (Boal, 1979, 2013).

Para representar o teatro do oprimido, Boal escolheu a árvore como símbolo (Figura 1), dada a constante transformação e capacidade de multiplicação desse organismo. A árvore estaria representando a estrutura pedagógica do método que se caracteriza por possuir ramificações coerentes e essencialmente interdependentes (Santos, 2009).

O teatro do oprimido é composto por diferentes técnicas que foram surgindo como respostas às demandas efetivas da realidade. Todas têm a mesma origem no solo fértil da ética, política, história, filosofia, economia e solidariedade, local onde a árvore vai atrás do nutriente da sua seiva para sobreviver e desenvolver a sua proposta metodológica. A solidariedade entre semelhantes é elemento basilar no teatro do oprimido, uma vez que não se deve somente conhecer as pressões individuais, mas também as pressões das outras pessoas (Boal, 2013).

Figura 1

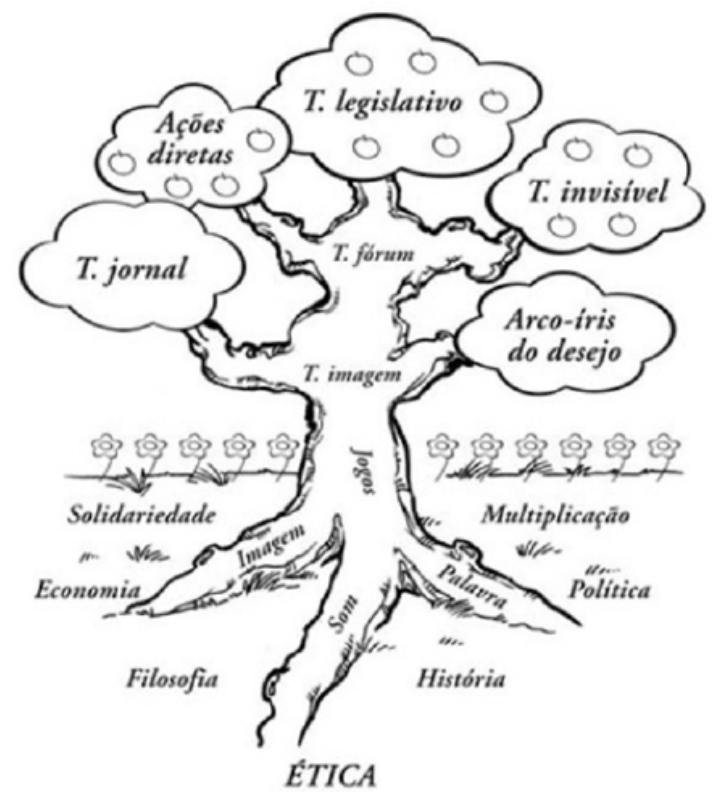

Fonte: adaptado de Teixeira e Teruel (2009, p. 66). 
Na raiz da árvore estão os três elementos com os quais se percebe o mundo: a palavra, o som e a imagem. A estética do oprimido estimula a descoberta das possibilidades produtivas e criativas por meio desses elementos para a promoção da sinestesia artística que impulsiona o autoconhecimento, a autoestima e a autoconfiança (Boal, 2009; Santos, 2009).

Logo em cima, no tronco da árvore, estão os jogos, que reúnem duas características essenciais na vida em sociedade: as regras e a liberdade criativa. Boal (2013, p. 16) pontuava que "sem regras não há jogo, sem liberdade não há vida", pois as regras - assim como as leis na sociedade - são necessárias para que os jogos aconteçam, mas a liberdade criativa é necessária para que o jogo - assim como a vida - não se transforme em servil obediência. Ademais, os jogos, por meio do estabelecimento de diálogos sensoriais que têm a criatividade como essência, também proporcionariam a desmecanização do corpo e da mente, uma vez que estes encontram-se habitualmente alienados das tarefas repetitivas do dia a dia, especialmente as do trabalho, e das condições econômicas, ambientais e sociais de quem os pratica.

Em cada uma das ramificações representadas pelos galhos, encontram-se as diferentes técnicas teatrais que têm características próprias e podem ser utilizadas em diversas circunstâncias, como o teatro-fórum, o teatro imagem, o teatro invisível, o teatro jornal, o arco-íris do desejo, o teatro legislativo e as ações diretas (Boal, 2009, 2013).

O teatro-fórum é a técnica de teatro do oprimido mais democratizada, sendo conhecida e praticada em todo o mundo. Numa peça de teatro-fórum, apresenta-se uma cena baseada em fatos reais, em que personagens oprimidos e opressores entram em conflito, de forma clara e objetiva, na defesa de seus desejos e interesses. Esse conflito incita a busca por alternativas para o problema encenado. Nesse sentido, os 'espect-atores' são convidados a entrar em cena para, por meio da atuação teatral - e não apenas com o uso da palavra -, revelar seus pensamentos, desejos e estratégias. Tais percepções irão sugerir uma gama de alternativas possíveis inventadas pelos próprios indivíduos pertencentes àquele grupo para a transformação da sociedade no sentido da libertação dos oprimidos.

Já o teatro imagem parte do pressuposto de que a arte é a de verdades por meio dos nossos aparelhos sensoriais. Essa técnica dispensa o uso da palavra para que seja possível o desenvolvimento de outras formas perceptivas que façam o uso do corpo, fisionomias, objetos, distâncias, cores, por exemplo. Utiliza-se da linguagem corporal para a compreensão dos fatos, problemas, pensamentos e sentimentos que estão por trás de determinada imagem. Tem como objetivo ampliar a visão sinalética, na qual significantes e significados são indissociáveis, para superar as restrições da linguagem simbólica das palavras, em que as realidades concretas e sensíveis são dissociadas. 
O teatro invisível realiza apresentações teatrais de forma não revelada em qualquer lugar onde aquela determinada trama (representação cotidiana de um tipo de opressão ou conflito) poderia realmente ocorrer ou já tenha efetivamente ocorrido, como na rua, na praça, no supermercado, na feira, na fila do ônibus, no cinema, entre outros locais. O público ocasional que está presente durante a 'atuação' vai reagindo e dando opiniões de forma espontânea, mas essas pessoas não são conscientes de suas condições de espectadores e participam de todo o processo sem saber, pois nem durante nem depois de uma cena de teatro invisível é informado que aquilo se tratou de teatro. Provoca-se a interpenetração da ficção na realidade e a da realidade na ficção: todos os presentes podem intervir a qualquer momento na busca de soluções para os problemas tratados. Os atores e espectadores encontram-se no mesmo nível de diálogo e de poder, não existindo antagonismo entre a sala e a cena, mas sim superposição.

Por sua vez, o teatro jornal, já mencionado, conjuga 12 técnicas de transformação de textos jornalísticos em cenas teatrais, combinando imagens e palavras. Nas suas imagens, são revelados significados que, nas palavras, haviam sido ocultados. Portanto, o teatro jornal tem como objetivo contribuir para a desconstrução e o desmascaramento do que se lê, colocando em evidência as manipulações utilizadas pelos meios de comunicação.

O arco-íris do desejo é formado por técnicas introspectivas que, por meio do uso de imagens e palavras, permitem a teatralização de opressões introjetadas e subjetivas bastante dolorosas para quem as sofre. Apesar de as técnicas se voltarem para dentro de cada um dos sujeitos, sempre se buscam ressonâncias no grupo, uma vez que o objetivo do arco-íris do desejo é mostrar que as opressões internalizadas têm sua origem na vida social e guardam íntima relação com ela. Mediante a identificação das opressões, objetiva-se a conscientização e posterior transformação.

O teatro legislativo constitui-se de um conjunto de procedimentos que mesclam o teatro-fórum e os rituais convencionais de uma câmara ou assembleia legislativa, objetivando a formulação de projetos de lei coerentes e viáveis. Em contato com a população, são debatidos os seus problemas reais e concretos para que então se realizem cenas que demonstrem essas questões e os 'espect-atores' possam entrar e dar suas sugestões. A partir disso, encaminham-se sugestões escritas para a criação de propostas legislativas, as quais são analisadas, sistematizadas e votadas pela plateia para, por fim, serem enviadas aos órgãos capazes de dar os devidos encaminhamentos.

As ações diretas consistem em teatralizar manifestações como protestos, marchas de camponeses, procissões laicas, desfiles, concentrações operárias e comícios de rua, por exemplo, utilizando-se todos os elementos teatrais convenientes, como máscaras, canções, danças, coreografias, entre outros. 
Por fim, o objetivo de toda árvore é dar flores, frutos e sementes, o que remete à multiplicação. Os frutos que caem ao solo servem para se reproduzir pela multiplicação. O teatro do oprimido cria uma sinergia que aumenta o seu poder transformador na medida em que se expande, uma vez que o horizonte dessa metodologia não é apenas o conhecimento da realidade, mas sim a transformação dela (Boal, 2013).

Berger (2014) aponta que, durante as décadas de 1980 e 1990, o teatro do oprimido se espraiou sobre diversas faces da questão social no Brasil e no mundo, como em discussões étnicas, de gênero, orçamento participativo, fóruns, conselhos, Movimento dos Trabalhadores Rurais Sem Terra (MST), movimentos da terceira idade, saúde, por exemplo. Também são relatadas algumas experiências que recorreram ao teatro do oprimido nas ações de promoção da saúde (Ahrens, Rich e Ullman, 2011; Gazzinelli et al., 2012; Leme, 2005; Santiago, 2000; Santos, Joca e Alves e Souza, 2016; Séguin e Rancourt, 1996; Silva, 2008; Sullivan et al., 2008; Tarasoff et al., 2014), o que nos dá pistas sobre as potencialidades desse método para as práticas de saúde, em particular de promoção da saúde.

\section{Promoção da saúde: conceituações e práticas}

O modelo biomédico, centrado na identificação e prevenção ou correção de disfunções e dismorfias, apresenta uma hegemonia histórica no campo da saúde, repercutindo na maneira como o cuidado tem sido destinado aos indivíduos e coletividades na nossa sociedade. Apesar de sua inegável importância para a sociedade, em geral, e para as práticas de saúde, em particular, é patente a sua associação com o fato de ele ser crescentemente caudatário dos interesses do complexo médico-industrial, o que, paradoxalmente, pode resultar em riscos e danos à saúde. Ao lado das motivações políticas e ideológicas, isso fez com que surgisse um pensamento crítico para o enfrentamento de tal problema e voltado para revalorizar as dimensões sociais e culturais do processo saúde-doença: o paradigma da promoção da saúde (Carvalho e Buss, 2012).

A proposta da promoção da saúde afina-se com as estratégias que visam superar a orientação predominantemente centrada no controle da enfermidade nas práticas de saúde, partindo de uma definição positiva de saúde que concebe saúde como produção social e realçando as suas determinações econômicas e sociais (Brasil, 2002).

Buss (2003) aponta que a evolução do conceito de promoção da saúde transitou de um dos níveis de prevenção no modelo de história natural da doença para um 'enfoque político e técnico' do processo saúde-doença-cuidado. 
Os primórdios da utilização do conceito de promoção da saúde remontam a Winslow, que a definiu como "um esforço da comunidade organizada para alcançar políticas que melhorem as condições de saúde da população e os programas educativos para que o indivíduo melhore a sua saúde pessoal" (Buss, 2003, p. 23). Em 1946, Sigerist propõe que a promoção da saúde, juntamente com a prevenção das doenças, a recuperação dos enfermos e a reabilitação, seria uma das quatro tarefas essenciais da medicina, defendendo a ideia de que "a saúde se promove proporcionando condições de vida decentes, boas condições de trabalho, educação, cultura física e formas de lazer e descanso" (Buss, 2003, p. 19).

Leavell e Clark (1976) desenvolvem o modelo da história natural da doença, organizando níveis das intervenções humanas - denominadas pelos autores como 'medidas preventivas' - no processo saúde-doença. A promoção da saúde seria uma medida incluída no primeiro período, a pré-patogênese, momento em que as manifestações clínicas das doenças ainda não surgiram nos indivíduos, apesar de já existirem condições tanto no ambiente quanto no patrimônio biológico deles para o aparecimento das doenças. Esses autores entendiam a promoção da saúde como medidas preventivas adotadas para aumentar a saúde e o bem-estar geral, não sendo focalizadas para alguma doença em específico, como educação sanitária, adequado padrão nutricional, atenção ao desenvolvimento da personalidade, moradia adequada, por exemplo.

Na década de 1970, publica-se o Informe Lalonde, documento relacionado à reforma do sistema de saúde canadense, com a proposta de colocar a promoção da saúde no contexto do pensamento estratégico juntamente com a regulação, a eficiência da assistência médica, a pesquisa e a fixação de objetivos. Os componentes desta estratégia de promoção da saúde se relacionavam ao ambiente físico e, com maior vigor, a fatores específicos do estilo de vida, como a dieta, o tabaco, o álcool, as drogas e a conduta sexual (Buss, 2003).

Já em 1986, realiza-se em Ottawa, Canadá, a $1^{\text {a }}$ Conferência Internacional de Promoção da Saúde. Deste encontro, derivou-se a Carta de Ottawa, um dos documentos fundadores do movimento atual da promoção da saúde (Buss, 2003). Nela, promoção da saúde é entendida como o

(...) processo de capacitação da comunidade para atuar na melhoria de sua qualidade de vida e saúde, incluindo uma maior participação no controle deste processo. Para atingir um estado de completo bem-estar físico, mental e social os indivíduos e grupos devem saber identificar aspirações, satisfazer necessidades e modificar favoravelmente o meio ambiente. A saúde deve ser vista como um recurso para a vida, e não como objetivo de viver (Brasil, 2002, p. 19).

De acordo com a Carta de Ottawa, "as condições e os recursos fundamentais para a saúde são: paz, habitação, educação, alimentação, renda, ecossistema 
estável, recursos sustentáveis, justiça social e equidade" (Brasil, 2002, p. 20), propondo-se cinco campos de ação para a promoção da saúde: a elaboração e a implementação de políticas públicas saudáveis; a criação de ambientes favoráveis à saúde; o reforço da ação comunitária; o desenvolvimento de habilidades pessoais; e a reorientação do sistema de saúde.

Nesse sentido, é interessante observar a classificação proposta por Sutherland e Fulton (apud Buss, 2000) acerca das diferentes apreensões sobre promoção da saúde entre aquelas que a entendem como atividades dirigidas à transformação dos comportamentos dos indivíduos, atuando principalmente sobre os estilos de vida - a denominada promoção da saúde behaviorista; e aquelas que dão ênfase ao papel de protagonista dos determinantes gerais sobre as condições de saúde, entendendo saúde como produto de um amplo espectro de fatores relacionados com a qualidade de vida e com abordagem prioritariamente voltada ao coletivo de indivíduos e ao ambiente.

A despeito do seu principal sentido, de politização e busca de aproximação entre saberes científicos e técnicos com os saberes populares, mediante a participação ativa dos indivíduos e comunidades em sua vida cotidiana e, consequentemente, no controle sobre os determinantes dos processos saúdedoença, a nova promoção da saúde ainda enfrenta grandes desafios. A aspiração à maior participação de pessoas e grupos nos processos saúde-doença tem sido apreendida sobretudo como responsabilização dos indivíduos pela saúde, privilegiando iniciativas educativas que visam a mudanças nos estilos pessoais de vida, com base nos saberes biomédicos (Polland, 2007).

De acordo com essas considerações, é possível retomar as indagações acerca das possibilidades de aproximações entre o teatro do oprimido e a promoção da saúde.

\section{Experiências práticas}

São poucos os relatos sobre experiências ou ensaios que estabelecem as possíveis aproximações entre teatro do oprimido e promoção da saúde (Paro, 2015). Dentre elas, destacamos algumas que explicitaram mais claramente os processos desenvolvidos e os resultados almejados e alcançados.

Um equívoco muito comum é associar ingenuamente o uso de ferramentas artísticas como música, dramatizações e até mesmo o teatro do oprimido com metodologias problematizadoras, com finalidades emancipatórias e de transformação da realidade, como foi a utilização de técnicas teatrais com os opressores em vez dos oprimidos na educação de profissionais de centros de reprodução humana assistida em relação aos pacientes LGBTQ (lésbicas, gays, bissexuais, travestis/transexuais e queers) (Tarasoff, 2014).

Sullivan e colaboradores (2008) fazem o relato sobre o Community Environmental Forum Theatre, experiência de justiça ambiental com uma in- 
terface translacional que conecta as atualidades científicas em toxicologia, epidemiologia e pesquisa clínica com as comunidades que precisam de tais informações para o combate à exposição de agentes tóxicos, a fatores de riscos e estressores acumulativos ambientais que impactam o bem-estar das coletividades. Como transformações relatadas por esses autores na realidade estudada por meio do teatro do oprimido, destacam-se: empoderamento dos envolvidos, advocacy para lutar contra injustiças ambientais, aprimoramento da habilidade de expressar conceitos e sentimentos e o aumento da autoestima, autoconfiança e autoeficácia.

Já Séguin e Rancourt (1996) relatam a experiência de projetos comunitários desenvolvidos em Mali e Canadá relacionados à saúde da mulher (com foco no planejamento familiar, menopausa e modos de vida saudáveis), à atenção aos portadores de transtornos mentais e à prevenção de HIV. Dentre as transformações atingidas, os autores apontam a superação de muitos tabus e preconceitos e a experiência (ainda que teatral) no combate à opressão, uma vez que o teatro propicia que as pessoas pensem questões sobre determinadas temáticas, as digam em voz alta e atuem, processo que é identificado como um poderoso agente de transformação pelos autores.

Silva (2008), com base na análise das percepções dos profissionais e usuários de uma unidade básica de saúde situada em comunidade carioca sobre a relevância do uso do teatro do oprimido nas ações de promoção da saúde, ressalta que nos processos em que se utiliza essa ferramenta abordam-se temas que as "próprias pessoas escolhem para debater e encontrar possíveis caminhos de saída, ou de entrada" (Silva, 2008, p. 129).

O estímulo à participação comunitária nos processos teatrais está diretamente relacionado à dimensão dialógica que compõe a essência do teatro do oprimido. Este se opõe à imposição da unilateralidade coercitiva do monólogo derivada da limitação do direito ao diálogo e propõe que todo mundo pode ensinar e todo mundo pode aprender (Boal, 2003).

No contexto da saúde mental, Santos, Joca e Souza (2016) relatam intervenção de projeto com o teatro do oprimido desenvolvido com usuários, familiares e trabalhadores em um centro de atenção psicossocial (Caps) de Fortaleza, Ceará. Quanto às transformações observadas, mencionam o processo de conquista e exercício da cidadania por parte dos usuários e seus familiares, pois estes adotaram novas formas de enfrentar as opressões que eram tidas como adoecedoras, assim como houve alteração na rotina e nos fluxos do serviço, o que repercutiu na gestão e na organização do Caps para acolher o grupo que participou do projeto.

Além das experiências enumeradas, ressalta-se a possibilidade de operacionalizar a experiência de utilização do teatro do oprimido na promoção da saúde por meio da criação de grupos de teatro do oprimido (GTOs), pois 
"tendo a essência comunitária do Teatro do Oprimido como referência, a questão da formação de núcleos de base se torna essencial" (Santos, 2016, p. 360).

Esses grupos buscam agregar indivíduos que se motivam a encontros periódicos de forma contínua e sistemática para discussão de seus problemas interpessoais e sociais, podendo ser temáticos para discussão de determinada questão - como por exemplo o GTO Pirei na Cena, formado por usuários do Hospital Psiquiátrico de Jurujuba e seus familiares em Niterói, no Rio de Janeiro, e o GTO Marias do Brasil, formado por trabalhadoras domésticas no Rio de Janeiro (RJ) (Rodrigues, 2016).

Além dos encontros e vivências teatrais, os GTOs normalmente encenam espetáculos para que as discussões ali desenvolvidas possam atingir os demais membros da sociedade. Esse processo é enriquecedor tanto para quem participa do grupo quanto para aqueles que participam de suas encenações.

Cada vez que um grupo popular apresenta seu espetáculo para uma nova plateia, entende melhor o problema que encena e descobre outras possibilidades de ação a partir do olhar alheio do espectador que entra em cena para improvisar uma alternativa. Cada plateia que assiste, ou melhor, que participa de uma sessão de Teatro-Fórum, descobre algo com a cena apresentada, com as intervenções e suas propostas e com a discussão desenvolvida, e leva para casa o movimento gerado no evento (Rodrigues, 2016, p. 64).

Vale ressaltar que o estímulo à criação de grupos comunitários não é uma tarefa simples. A efetivação de um processo grupal que tenha como diretrizes ser dialógico, crítico, libertário e transformador exige um constante processo de ação-reflexão-ação. Este não está livre de movimentos de desconstrução, reconstrução e apropriação coletiva/individual do objetivo e dinâmica do grupo, demandando, portanto, respeito às distintas temporalidades necessárias para a sua formação (Zimerman, 2000).

Para a organização e a coordenação dos GTOs existe a figura do curinga, artista-ativista em constante processo de aprendizagem que atua como facilitador do método. E para exercer sua função, ele deve conhecer os fundamentos éticos, políticos, estéticos, pedagógicos e filosóficos do método, assim como as técnicas que integram o seu arsenal. O curinga também está apto a ministrar oficinas e cursos teóricos e práticos, orientar processos estéticos e produções artísticas, dirigir montagens de cenas e de espetáculos, facilitar diálogos teatrais, estimular e articular ações sociais concretas e continuadas, sistematizar teoricamente a experiência da prática e contribuir para o desenvolvimento do método (Santos, 2016).

Depreende-se, portanto, que a utilização dessa ferramenta na promoção da saúde exige a formação de profissionais da área para poderem ocupar o 
papel de curinga. No entanto, vale ressaltar que também é possível realizar tais ações por meio de outros arranjos, como a articulação com o trabalho desenvolvido em GTOs já existentes; a formação de lideranças comunitárias que possam se tornar curingas em centros formadores de teatro do oprimido e desenvolver o método nos seus contextos locais; ou o estabelecimento de parcerias com curingas para o desenvolvimento de projetos e ações.

No entanto, apostar em estratégias inovadoras para se promover saúde, como aquelas advindas do teatro do oprimido, exige instaurar mudanças no interior dos próprios serviços, equipes e setores gerenciais de saúde. Isso inclui desde a necessidade de reformulações na formação dos profissionais de saúde até a instauração de novos paradigmas nos modelos assistenciais. Não se pode ser democrático e problematizador em relação à população quando são experimentadas relações antidemocráticas, autocráticas e não participativas no processo de trabalho e na gestão do trabalho.

Diante dos esforços para a incorporação, nas ações de promoção da saúde, dos princípios e estratégias do teatro do oprimido, indicando as suas potencialidades, vale refletir sobre os pontos de congruência e dissonância em torno de conceitos e referências que os apoiam.

\section{Aspectos conceituais}

No cotidiano dos serviços e ações de saúde, as estratégias de intervenção sobre os comportamentos individuais não saudáveis continuam centrais nas práticas de promoção da saúde. Promover saúde nessa perspectiva tem sido sinônimo de conseguir responsabilizar os indivíduos sobre os efeitos deletérios que os hábitos de vida não saudáveis adotados por eles têm sobre a sua própria saúde. O objetivo central dessas ações dá ênfase, portanto, nas mudanças por meio das decisões individuais estritamente. Para tanto, estas devem ter como foco a transferência de conhecimentos, permeada por um discurso biologicista, higienista e normalizador, muito comum em campanhas contra o fumo, hipertensão e diabetes, por exemplo (Meyer et al., 2006).

Apesar de as intervenções nessa perspectiva até poderem apresentar efeitos positivos em relação à adoção de estilos e hábitos de vida mais saudáveis por parte de algumas pessoas, elas vêm, no seu conjunto, obtendo impacto limitado sobre as condições de vida da população, em especial daquela que vive em contextos de maior vulnerabilidade social aos diversos agravos à saúde. Essa abordagem,

ao escamotear as mazelas e estruturas sociais causadoras da não saúde, poderia servir de anteparo à implementação de políticas neoliberais socialmente restritivas, culpabilizando, no processo, as vítimas (blaming the victims) da iniquidade social (Carvalho, 2004b, p. 1.089). 
O risco da penalização dos indivíduos, mediante o estabelecimento de critérios discutíveis de homogeneização de comportamentos, configura-se pela agudização do autoritarismo sanitário, diminuindo a margem de autonomia das pessoas, dos grupos humanos e das coletividades. Ademais, a responsabilização das pessoas por estilos de vida tidos como não saudáveis desvia a discussão de fatores sociais, ambientais e econômicos, assim como sobre as condições de trabalho que influem fortemente no processo saúde-doença (Batistella, 2007).

Nesse sentido, Carvalho (2005) critica a promoção da saúde behaviorista por atuar na manutenção do status quo, uma vez que sua estratégia de intervenção sobre estilos de vida é tida como justificativa para o não enfrentamento das causas da iniquidade na distribuição de recursos e de poder na sociedade.

Diante desse cenário, observa-se uma incompatibilidade entre os pressupostos teórico-conceituais da promoção de saúde behaviorista e os alicerces éticos, estéticos e políticos que fundamentam o teatro do oprimido. Os pressupostos conceituais do teatro do oprimido giram em torno de cultura, cidadania e opressão em uma sociedade dividida em classes sociais (Boal, 1980). Nesse sentido, Boal assume:

Os que pretendem separar o teatro da política pretendem conduzir-nos ao erro - e essa é uma atitude política. (...) o teatro é uma arma. Uma arma muito eficiente. Por isso, é necessário lutar por ele. Por isso, as classes dominantes permanentemente tentam apropriar-se do teatro e utilizá-lo como instrumento de dominação. Ao fazê-lo, modificam o próprio conceito do que seja o 'teatro'. Mas o teatro pode igualmente ser uma arma de liberação. Para isso, é necessário criar as formas teatrais correspondentes. É necessário transformar (Boal, 2013, p. 13).

A partir desta assunção, verifica-se que o teatro do oprimido se afasta de qualquer tentativa de domesticação dos corpos e de normatização de comportamentos, hábitos e estilos para que sejam atingidos padrões (classificados por alguns como) saudáveis. Uma perspectiva de promoção da saúde afinada com o SUS, ao contrário dessa apreensão verticalizada e monológica do teatro do oprimido, fomentaria o diálogo e a participação dos sujeitos, com vistas à transformação social.

Assim, a mera utilização do teatro do oprimido somente como uma estratégia ou recurso para prescrever comportamentos e práticas desvia-se do seu sentido original de propiciar, por meio das diferentes técnicas, a problematização dos contextos macro e microssociais e a ampliação de espaços de politização. Essa apropriação instrumental, ao desvincular tal metodologia de suas apreensões políticas, implicará a redução do seu potencial transformador. Sobre isso, Julián Boal, filho de Augusto Boal, denuncia que: 
(...) os livros de Augusto Boal, assim como sua experiência, se propagaram mundo afora. Existem hoje trupes em mais de quarenta países. Algumas reduziram o Teatro do Oprimido a um conjunto de técnicas; outras souberam se inspirar nos textos para fundar experiências absolutamente fascinantes (Boal, 2013, p. 216).

Negar ou negligenciar os pressupostos axiológicos, políticos, éticos e estéticos incorre na descaracterização de todo o potencial dialógico, libertário e transformador desse teatro, já que o reduz a um mero conjunto de técnicas de dramatização sob o mote de se usarem atividades interativas, dinâmicas e 'mais participativas'. Para Boal,

se um espectador que não sofre a mesma opressão trata de substituir o protagonista oprimido, é claro que cairemos no teatro exemplar: uma pessoa mostrando a outra o que ela deve fazer - o velho teatro evangelista, o teatro político de antigamente (Boal, 2002, p. 340).

O manejo da técnica junto aos opressores não teria todo o potencial emancipatório e de transformação social porque "a liberação do oprimido será obra do próprio oprimido, jamais será outorgada por seu opressor" (Boal, 1980, p. 83). Assim, esse potencial deve ser utilizado com os oprimidos, buscando só posteriormente um diálogo cênico com os demais atores sociais que compõem a realidade.

Em contraponto à vertente behaviorista da promoção da saúde, vislumbra-se aquela que, afinada com os pressupostos da nova promoção da saúde, enfatiza o papel protagonista dos determinantes sociais sobre o processo saúde-doença (Carvalho, 2004a). Nessa perspectiva, saúde é entendida como produto de um amplo espectro de contextos individuais, sociais e políticoinstitucionais que, em conjunto, podem conformar diferentes patamares de qualidade de vida: condições de trabalho, oportunidades de educação ao longo de toda a vida, ambiente físico limpo, apoio social para famílias e indivíduos, cuidados de saúde adequados e padrões adequados de alimentação, nutrição, habitação e saneamento. Nesse sentido, suas ações estão tanto voltadas para o nível individual quanto para o nível ambiental. O ambiente apresenta aqui uma acepção ampla, que engloba os ambientes físico, econômico, político, social e cultural. Tais ações se concretizam por meio de políticas públicas e condições favoráveis ao desenvolvimento da saúde (Buss, 2000) que, mais do que 'concessões' do Estado, devem ser expressão da vontade e conquista da população, possível segundo a capacidade dos indivíduos e das comunidades de se mobilizarem nessa direção.

Na nova promoção da saúde, tal capacidade tem sido nomeada de empoderamento. Trata-se de um dos seus núcleos filosóficos e estratégias-chave, a 
partir da qual se espera "capacitar e(ou) possibilitar (enable) que indivíduos e coletivos se preparem para responder, de maneira criativa, aos desafios biopsicológicos e sociais da vida social" (Carvalho, 2005, p. 62). No contexto brasileiro, esta noção é considerada, inclusive, como um dos valores da própria Política Nacional de Promoção da Saúde (Brasil, 2014).

No plano conceitual, ao comparar essa vertente da promoção da saúde com os fundamentos éticos, estéticos e políticos da proposta de Boal, Leme assume que

a proposta do Teatro do Oprimido vem ao encontro das demandas eliciadas pela Promoção da Saúde, dado que propõe formas de capacitação para a atividade política de forma interativa, crítica e contextualizada com os valores de uma dada comunidade-foco (Leme, 2005, p. 127).

Diante dessa afinidade, o autor propõe que o arsenal do teatro do oprimido pode ser utilizado como mais um instrumento de qualificação de sujeitos para a promoção da saúde, pois "funciona como um subsídio que lhes dá condições de contribuir para a concreção de uma sociedade mais saudável e equânime" (Leme, 2005, p. 128).

Das críticas à noção de empoderamento, destaca-se aquela que se preocupa com o seu sentido prático usual, identificado com uma vontade individual, desprovida dos contextos sociais aos quais se articula. Com tal preocupação e afinando-se com o jargão das correntes teóricas críticas, Paiva (2002) propõe a utilização do conceito de emancipação.

Segundo Seffner, Pupo e Paiva (2012), a emancipação pode expressar três sentidos, relevantes para as práticas de saúde, como ferramenta de estratégia política, um conceito ou um projeto político:

Há autores que consideram a emancipação mais na esfera do projeto político (o desenho da utopia de uma sociedade futura) enquanto outros a definem como uma categoria de análise de processos políticos (como um indicador para fazer análise de processos ético-políticos, que produzem a emancipação de indivíduos, grupos ou países), ou, ainda, pode ser privilegiada como ferramenta político-pedagógica, ao falar de estratégias de emancipação (ações que podem implicar em ampliação da consciência pessoal que contribui para a emancipação dos indivíduos) (Seffner, Pupo e Paiva, 2012, p. 13).

Nesse sentido, pode-se dizer que o teatro do oprimido conduz a uma emancipação em todas as esferas apontadas, promovendo o exercício e a capacitação para a reflexão e a ação. Esse teatro permite que seja recriada a realidade a partir da oferta de possibilidades para soluções aos problemas 
sociais (Neves, 2015). Uma vez que inclusive a escolha sobre esse problema se dá pelo próprio grupo e não por aquele que propõe a ação, consegue-se por meio dessa técnica falar com as pessoas, em vez de falar sobre elas. Tal maneira de se atuar permite que os processos de emancipação se concretizem 'com' o outro em vez de 'sobre' o outro.

A respeito do teatro do oprimido como uma ferramenta de participação popular, Teixeira comenta:

a técnica teatral é empregada como um método de educação popular, que contribui para a compreensão do indivíduo e contextualização dos fatos sociais. Nem sempre os canais formais de participação social são suficientes para detectar as demandas da população. No ambiente formal das reuniões, nem sempre as pessoas se sentem desinibidas para se manifestarem, o que prejudica a discussão de temas importantes. Promover a participação popular exige a procura de novas linguagens que favoreçam ao diálogo entre governo e população, criando novos espaços onde a expressão criativa dos indivíduos seja estimulada. A participação popular é um componente fundamental para consolidação da democracia. Para que esta participação se torne efetiva, é necessário um trabalho educativo que ajude a população a entender os aspectos envolvidos nas relações de poder. Na vida cotidiana, observamos situações de opressão, discriminação e preconceitos não discutidos e muitas vezes não resolvidos (Teixeira, 2005, p. 4).

Assim, sendo o teatro uma linguagem essencialmente humana - dada a máxima de Boal (2005, p. 9) "ser humano é ser teatro, e ser teatro é ser humano" -, é possível pensar nessa linguagem como uma alternativa de participação social válida e potente, tão cara ao SUS. O teatro do oprimido pode propiciar o debate das questões públicas, estimular a criatividade e a capacidade da própria comunidade em propor alternativas para as questões do cotidiano e, principalmente, ter a perspectiva do próprio povo na análise dos fenômenos sociais (Boal, 1979).

Uma das grandes influências das práticas de educação em saúde (Alves, 2005), o educador Paulo Freire (2011) destacou a importância do diálogo e da participação como elementos pedagógicos do processo educativo. O diálogo pedagógico oportuniza a participação de todos os envolvidos e implica um saber crítico que possibilita uma práxis, uma ação-reflexão: “é por meio do diálogo e da participação que o conhecimento apreendido, o conteúdo ou objeto cognoscível constrói-se, gerando novas formas de conhecimento com base nas experiências" (Lopes e Tocantins, 2012, p. 240).

Nesse sentido, a utilização de dispositivos dialógicos que propiciem uma educação crítica como o teatro do oprimido é necessária para atender às exigências do campo da promoção da saúde, uma vez que este atua no sentido 
da formação consciente dos sujeitos e mediação com a sua realidade social para a transformação social e coletiva (Lopes e Tocantins, 2012).

Para a superação desses monólogos que fazem parte do nosso cotidiano, Boal sustenta a importância da criação de espaços de diálogo. O teatro, como arte que organiza as ações humanas no espaço e no tempo, é um deles.

[As práticas teatrais,] ao organizarem ações humanas, mostram onde se esteve, onde se está e para onde se vai: quem somos, o que sentimos e desejamos. Por isso, devemos fazer teatro, todos nós: para saber quem somos e descobrir quem podemos vir a ser (Boal, 2003, p. 90).

Além de diálogo entre os sujeitos, o que se tem como grande desafio é a promoção de um diálogo entre os discursos da saúde e a cultura, buscando uma harmonização desses discursos por meio de uma composição que tenha como horizonte ético maior autonomia e empoderamento de sujeitos e coletivos.

Freire (2016) descreve o processo de conscientização como aquele em que o homem não somente toma consciência de sua realidade, mas também o faz de forma crítica e se compromete com mudanças concretas, de transformação da sua realidade. Parece que o teatro do oprimido tem potencial nessas duas etapas do processo de conscientização. É útil tanto para os processos de tomada de consciência quanto para a transformação social.

No tocante à tomada de consciência, observa-se que a possibilidade de compreensão de si e do mundo a sua volta pelo teatro se dá pelo fato de este, por meio da prática de jogos, exercícios e técnicas teatrais, estimular a discussão e a problematização de questões do cotidiano, tendo como objetivo maior reflexão sobre as relações de poder (Sullivan et al., 2008; Teixeira, 2007).

Sobre a temática da transformação da realidade, Boal $(2013$, p. 18) ressalta que "o Teatro do Oprimido, em todas as suas formas, busca sempre a transformação da sociedade no sentido da libertação dos oprimidos. É a ação em si mesmo, e é a preparação para ações futuras".

Nesse sentido, sendo o teatro do oprimido entendido como um "ensaio para o futuro", Boal sempre reforçava que "o espetáculo é o início de uma transformação social necessária e não um momento de equilíbrio e repouso. $O$ fim é o começo!" (Boal, 2013, p. 18; destaques no original). Dentre as repercussões do potencial transformador do teatro do oprimido, Teixeira (2007) aponta o estímulo à desopressão, incentivando o exercício democrático participativo.

O desafio para se promover saúde tem sido a construção de espaços participativos inovadores de escuta, diagnóstico e análise coletiva dos problemas de saúde pública e dos contextos que afetam o bem-estar, vulnerabilizando indivíduos e coletivos. Assim, metodologias relacionais alternativas e novas sensibilidades, como o próprio teatro do oprimido, devem ser exploradas 
como dispositivos dialógicos que visam à formação consciente de sujeitos e mediação com a sua realidade social para a transformação social e coletiva.

A articulação do teatro do oprimido com as ações de promoção da saúde parece potente, considerando que diversas opressões existentes na nossa sociedade são produtoras de iniquidades em saúde (Buss e Pellegrini Filho, 2006), como o sexismo, o machismo e o patriarcado; a homofobia, a lesbofobia e a transfobia; o racismo; o etnocentrismo e a xenofobia; e as diversas formas de discriminação, estigmatização e violência de determinados grupos societários, como os portadores de transtornos mentais, moradores de favela, pessoas vivendo com HIV/Aids, trabalhadoras domésticas, pessoas que têm determinadas doenças com representações sociais negativas, entre tantas outras.

Os aspectos mencionados estão diretamente relacionados à maneira como historicamente as sociedades se organizaram, às influências dos regimes político-econômicos aos quais as sociedades foram submetidas e às construções de relações sociais e significados presentes nas diversas matrizes culturais, principalmente nas classes sociais dominantes e sociedades que exercem dominações sobre outras. Muitos desses fatores devem ser superados e combatidos para que possamos possibilitar que diversos grupos sociais marginalizados ou discriminados possam usufruir de uma vida saudável e com qualidade de vida, conforme preconizam os pressupostos da promoção da saúde (Brasil, 2002).

Desse modo, parece coerente a aproximação entre teatro do oprimido e promoção da saúde, o que é um importante dispositivo para alcançar muitos dos elementos almejados pela promoção da saúde, como a participação popular no processo de cuidado com a criação de espaços de diálogos mais participativos; a implantação/implementação de políticas públicas saudáveis com a instauração de processos dialógicos mais participativos; e a emancipação de sujeitos/coletivos com formação de sujeitos eticamente comprometidos com a transformação de sua realidade social (Paro, 2015).

As ideias de promoção da saúde 'pelo' e 'com' o povo e não 'sobre' o povo (Organização Mundial da Saúde, 1997, p. 6) e de teatro do oprimido como o teatro 'dos' oprimidos, 'para' os oprimidos, 'sobre' os oprimidos (Boal, 2013, p. 26), podem ser a melhor expressão das convergências entre ambos.

\section{Considerações finais}

"Muito mais importante do que chegar a uma boa solução é provocar um bom debate."

Augusto Boal

Ao se compararem as características do teatro do oprimido com os princípios da promoção da saúde, observa-se que existem algumas consonâncias entre eles a partir do momento em que ambos logram o fortalecimento de práticas 
cidadãs questionadoras do status quo e mudanças sociais em prol de uma transformação libertária e crítica. No entanto, uma apropriação meramente técnica da metodologia do teatro do oprimido, despreocupada e desvencilhada de seus pressupostos políticos, é ineficaz como metodologia relacional para a promoção da saúde. Este uso, que pode ser mais considerado como um abuso, não representa uma possibilidade de mudança radical no modo atual de conceber e praticar saúde conforme idealizado pelo movimento da promoção da saúde, pois não leva em conta os anseios dos indivíduos e coletividades, assim como atua, predominantemente, segundo uma lógica da domesticação e do risco, culpabilizando os indivíduos ao adoecerem por não saberem cuidar de si.

Múltiplas conexões podem ser criadas entre teatro do oprimido e promoção da saúde, de modo a permitir a inventividade nos arranjos a partir do diálogo entre os atores sociais pertencentes a determinado contexto local. Esse diálogo deve ser potencializado numa perspectiva crítica de reinvenção, mudança e inovação, com o objetivo de que os indivíduos e coletividades possam atuar em melhorias de suas qualidades de vida e saúde.

\section{Colaboradores}

César Augusto Paro e Neide Emy Kurokawa e Silva participaram de todas as etapas da pesquisa e da redação do manuscrito. Os autores declaram não haver conflitos de interesses. 
Resumen El presente estudio objetivó analizar las aportaciones del teatro del oprimido en promoción para la salud logrando contribuir a la consolidación de este diálogo para que se potencie el impacto en el desarrollo de experiencias prácticas. Entre las dos principales perspectivas de la promoción de la salud, se ha observado una falta de correspondencia entre los fundamentos éticos, estéticos y políticos que subyacen al teatro del oprimido y los supuestos teóricos de la promoción de la salud behaviorista, ya que este teatro se aleja de cualquier intento de domesticación de los cuerpos y de regulación de comportamientos, hábitos y estilos de forma que se cumplan las normas (clasificados por algunos como) saludables. En cuanto a la perspectiva de la nueva promoción de la salud, su politización y busqueda de acercamiento entre los saberes científicos y técnicos con los saberes populares, hay una mayor consonancia entre ellos desde el momento en que ambos logran fortalecer la práctica de cuestionar el status quo y el cambio social hacia una transformación libertaria y crítica.

Palabras clave teatro del oprimido; empoderamiento; promoción de la salud; ciudadanía; participación popular.

\section{Notas}

${ }^{1}$ Universidade Federal do Rio de Janeiro, Programa de Pós-Graduação em Saúde Coletiva do Instituto de Estudos em Saúde Coletiva da Rio de Janeiro, RJ, Brasil.

$<$ cesaraugustoparo@iesc.ufrj.br>

Correspondência: Av. Horácio de Macedo, s/n, Ilha do Fundão, Cidade Universitária, CEP 21941-598, Rio de Janeiro, RJ, Brasil.

${ }^{2}$ Universidade Federal do Rio de Janeiro, Instituto de Estudos em Saúde Coletiva, Rio de Janeiro, RJ, Brasil.

$<$ neks@iesc.ufrj.br>

${ }^{3}$ Este artigo é resultado da monografia Teatro do oprimido e promoção da saúde: perspectivas e desafios, de César A. Paro, defendida no Curso de Residência Multiprofissional em Saúde Coletiva do Instituto de Estudos em Saúde Coletiva da Universidade Federal do Rio de Janeiro, em 2015. Como este trabalho não foi desenvolvido com seres humanos, não houve a submissão ao Comitê de Ética em Pesquisa. 


\section{Referências}

AHRENS, Courtney E.; RICH, Marc D.; ULLMAN, Jodie B. Rehearsing for real life: the impact of the InterACT Sexual Assault Prevention Program on self-reported likelihood of engaging in bystander interventions. Violence Against Women, Lexington, v. 17, n. 6, p. 760-776, 2011.

ALVES, Vânia S. Um modelo de educação em saúde para o Programa Saúde da Família: pela integralidade da atenção e reorientação do modelo assistencial. Interface: Comunicação, Saúde e Educação, Botucatu, v. 9, n. 16, p. 39-52, 2005.

BARBOSA, Inês B. Jovens e teatro do oprimido: (re)criando a cidadania, (re)construindo o futuro. 2011. 153 f. Dissertação (Mestrado em Estudos da Criança) - Universidade do Minho, Minho, 2011.

BATISTELLA, Carlos. Abordagens contemporâneas do conceito de saúde. In: FONSECA, Angélica F.; CORBO, Ana M. D’Andrea (orgs.). O território e o processo saúde-doença. Rio de Janeiro: EPSJV/Fiocruz, 2007. p. 81-86.

BERGER, William. Augusto Boal e o teatro do oprimido. Em Pauta, Rio de Janeiro, v. 33, n. 12, p. 109-133, 2014.

BOAL, Augusto. Técnicas latino-americanas de teatro popular: uma revolução copernicana ao contrário. São Paulo: Hucitec, 1979.

BOAL, Augusto. Stop: c'est magique!. Rio de Janeiro: Civilização Brasileira, 1980.

BOAL, Augusto. O arco-íris do desejo: o método Boal de teatro e terapia. Rio de Janeiro: Civilização Brasileira, 2002.

BOAL, Augusto. O teatro como arte marcial. Rio de Janeiro: Garamond, 2003.

BOAL, Augusto. International theatre for children and young people world day. In: SEMINÁRIO NACIONAL SESC - CENTRO
BRASILEIRO DE TEATRO PARA A INFÂNCIA E JUVENTUDE, 2004, Rio de Janeiro. Revista do... Rio de Janeiro: CBTIJ, 2005. p. 9-10. Disponível em: <http://cbtij.org.br/ wp-content/uploads/2014/09/cbtij-revistaseminario-nacional-02-2004.pdf $>$. Acesso em: 31 jan. 2015.

BOAL, Augusto. A estética do oprimido. Rio de Janeiro: Garamond, 2009.

BOAL, Augusto. Teatro do oprimido e outras poéticas políticas. 2. ed. São Paulo: Cosac Naify, 2013.

BRASIL. Ministério da Saúde. Secretaria de Políticas de Saúde. Projeto Promoção da Saúde. As cartas da promoção da saúde. Brasília: Ministério da Saúde, 2002.

BRASIL. Ministério da Saúde. Secretaria de Vigilância em Saúde. Secretaria de Atenção à Saúde. Política Nacional de Promoção da Saúde (PNPS): revisão da portaria MS/GM n. 687, de 30 de março de 2006. Brasília: Ministério da Saúde, 2014.

BUSS, Paulo M. Promoção da saúde e qualidade de vida. Ciência \& Saúde Coletiva, Rio de Janeiro, v. 5, n. 1, p. 163-177, 2000.

BUSS, Paulo M. Uma introdução ao conceito de promoção da saúde. In: CZERESNIA, Dina; FREITAS, Carlos M. (orgs.). Promoção da saúde: conceitos, reflexões, tendências. Rio de Janeiro: Editora Fiocruz, 2003. p. 15-38.

BUSS, Paulo M.; PELLEGRINI FILHO, Alberto. Iniquidades em saúde no Brasil, nossa mais grave doença: comentários sobre o documento de referência e os trabalhos da Comissão Nacional sobre Determinantes Sociais da Saúde. Cadernos de Saúde Pública, Rio de Janeiro, v. 22, n. 9, p. 2.005-2.008, 2006.

CARVALHO, Antonio I.; BUSS, Paulo M. Determinantes sociais na saúde, na doença e na intervenção. In: GIOVANELLA, Lígia 
et al. (orgs.). Políticas e sistema de saúde no Brasil. 2. ed. Rio de Janeiro: Editora Fiocruz, 2012. p. 121-142.

CARVALHO, Sérgio R. As contradições da promoção à saúde em relação à produção de sujeitos e a mudança social. Ciência \& Saúde Coletiva, Rio de Janeiro, v. 9, n. 3, p. 669$678,2004 a$.

CARVALHO, Sérgio R. Os múltiplos sentidos da categoria empowerment no projeto de promoção à saúde. Cadernos de Saúde Pública, Rio de Janeiro, v. 20, n. 4, p. 1.088-1.095, 2004b.

CARVALHO, Sérgio R. Saúde coletiva e promoção da saúde: sujeito e mudança. São Paulo: Hucitec, 2005.

FREIRE, Paulo. Conscientização. Tradução de Tiago José Risi Leme. São Paulo: Cortez Editora, 2016.

FREIRE, Paulo. Pedagogia da autonomia: saberes necessários à prática educativa. 43. ed. São Paulo: Paz e Terra, 2011.

GAZZINELLI, Maria F. et al. Teatro na educação de crianças e adolescentes participantes de ensaio clínico. Revista de Saúde Pública, São Paulo, v. 46, n. 6, p. 999-1.006, 2012.

\section{INTERNATIONAL THEATRE OF THE OPPRESSED} ORGANIZATION (ITO). Theatre of the oppressed in the world. 2015. Disponível em: <http:// www.theatreoftheoppressed.org/en/index. php?nodeID=2> . Acesso em: 28 jan. 2015.

LEAVELL, Hugh R.; CLARK, Edwin G. Medicina preventiva. São Paulo: McGraw-Hill, 1976.

LEME, Alexandre O. A teatralidade de Boal: possibilidades de promoção da saúde através da participação popular. Saúde Coletiva, São Paulo, v. 2, n. 8, p. 124-128, 2005.

LOPES, Rosane; TOCANTINS, Florence R. Promoção da saúde e a educação crítica. Interface: Comunicação, Saúde e Educação, Botucatu, v. 16, n. 40, p. 235-246, 2012.
MEYER, Dagmar E. E. et al. 'Você aprende. A gente ensina?' Interrogando relações entre educação e saúde desde a perspectiva da vulnerabilidade. Cadernos de Saúde Pública, Rio de Janeiro, v. 22, n. 6, p. 1.335-1.342, 2006.

NEVES, Mara I. V. O teatro do oprimido enquanto estratégia de promoção do empowerment em populações socialmente vulneráveis: estudo de caso do grupo de teatro do oprimido de Lisboa. 2015. 125 f. Dissertação (Mestrado em Política Social) - Instituto Superior de Ciências Sociais e Políticas, Universidade de Lisboa, Lisboa, 2015.

ORGANIZAÇÃO MUNDIAL DA SAÚDE (OMS). A declaração de Jacarta sobre promoção da saúde no século XXI. 1997. Disponível em: <http://bvsms.saude.gov.br/bvs/publicacoes/ declaracao_jacarta_1997.pdf > . Acesso em: 28 nov. 2014

PAIVA, Vera. Sem mágicas soluções: a prevenção e o cuidado em HIV/Aids e o processo de emancipação psicossocial. Interface: Comunicação, Saúde e Educação, Botucatu, v. 22, n. 6, p. 25-38, 2002.

PARO, César A. Teatro do oprimido e promoção da saúde: perspectivas e desafios. 2015. $95 \mathrm{f}$. Monografia (Residência Multiprofissional em Saúde Coletiva) - Instituto de Estudos em Saúde Coletiva, Universidade Federal do Rio de Janeiro, Rio de Janeiro, 2015.

POLLAND, Blake. Health promotion in Canada: perspectives \& future prospects. Revista Brasileira em Promoção da Saúde, Fortaleza, p. 20, n. 1, p. 3-11, 2007.

RODRIGUES, Monique. Grupos populares: 30 anos de história. Metaxis, Rio de Janeiro, n. 8, p. 36-39, 2016.

SANTIAGO, Lydia E. Teatro de la vida: teoría, método y práctica. Puerto Rico Health Sciences Journal, San Juan, v. 19, n. 1, p. 77-82, 2000.

SANTOS, Bárbara. A árvore do teatro do oprimido. Revista Paulo Freire: Revista de 
Formação Político-Pedagógica do Síntese, Aracaju, n. 3, p. 10-11, 2009.

SANTOS, Bárbara. Teatro do oprimido: raízes e asas - uma teoria da práxis. Rio de Janeiro: Ibis Libris, 2016.

SANTOS, Erika S.; JOCA, Emanuella C.; SOUZA, Angela Maria A. Teatro do oprimido em saúde mental: participação social com arte. Interface: Comunicação, Saúde e Educação, Botucatu, v. 20 , n. 58 , p. $637-647,2016$.

SEFFNER, Fernando; PUPO, Ligia R.; PAIVA, Vera. Educação em saúde e emancipação: explorando possibilidades da prevenção no quadro dos direitos humanos. In: PAIVA, Vera; PUPO, Ligia R.; SEFFNER, Fernando (orgs.). Pluralidade de vozes e inovação de práticas. (Coletânea Vulnerabilidade e Direitos Humanos: prevenção e promoção da saúde.). Curitiba: Juruá Editora, 2012. p. 9-26.

SÉGUIN, Angèle; RANCOURT, Clémence. El teatro, instrumento eficaz para la promoción de la salud. Foro Mundial de la Salud, Genebra, v. 17, n. 1, p. 66-71, 1996.

SILVA, Pedro J. P. A poética da promoção da saúde e o teatro do oprimido: percepções sobre a relevância do uso da linguagem teatral na Estratégia Saúde da Família do Complexo de Manguinhos (RJ), através da estruturação da ação-interdisciplinar teatro dentro da vida. 2008. 160 f. Dissertação (Mestrado em Saúde da Família) - Universidade Estácio de Sá, Rio de Janeiro, 2008.
SULLIVAN, John et al. Theatre of the oppressed and environmental justice communities. Journal of Health Psychology, Londres, v. 13, n. 2, p. 166-179, 2008.

TARASOFF, Lesley A. et al. Using interactive theatre to help fertility providers better understand sexual and gender minority patients. Medical Humanities, Londres, v. 40, n. 2, p. 135-141, 2014.

TEIXEIRA, Tânia M. B. Dimensões socioeducativas do teatro do oprimido de Augusto Boal: uma proposta de intervenção - Paulo Freire e Augusto Boal. Recrearte: Revista Internacional de Creatividad Aplicada Total, Santiago de Compostela, v. 4, p. 1-17, 2005.

TEIXEIRA, Tânia M. B. Dimensões socioeducativas do teatro do oprimido: Paulo Freire e Augusto Boal. 2005. 335 f. Tese (Doutorado em Educação e Sociedade) - Universidade Autônoma de Barcelona, Barcelona, 2007.

TEIXEIRA, Tânia M. B.; TERUEL, Tomás M. De Freire a Boal: Pedagogia del Oprimido/ Teatro del Oprimido. Ciudad Real: Ñaque Editora, 2009.

ZIMERMAN, David E. Fundamentos básicos das grupoterapias. Porto Alegre: Artmed, 2000.

Recebido em 07/08/2016. Aprovado em 09/06/2017. 